\title{
Reason and unreason in assessing risk
}

\section{Eric Ashby}

LAST November the Royal Society held a discussion meeting on the assessment and perception of risk. Among the speakers were engineers, toxicologists, psychologists, mathematicians, biologists, administrators; but there was no representative of the profession which makes its living out of risk-assessment: the actuaries who calculate insurance premiums. If the experts in this profession are not cautious enough, the firm loses money. If they are too cautious, the firm loses business. The impression left (upon me, at any rate) by this discussion was that research on riskassessment, though much of it is interesting and sophisticated, is not yet a reliable tool for people who have to make decisions in the public interest about hazardous projects. Statisticians can give accurate estimates of familiar risks. Social psychologists can give plausible descriptions of the way these risks are perceived. What we need is more evidence from the people who may lose their reputations or their jobs if they misjudge risks. With this in mind I welcomed the invitation to read two more books on this subject.

The book edited by Conrad is a record of a workshop organized by the Battelle Institute. There are 20 papers by authors from different countries. Part I covers familiar ground; it deals with the methods used in risk-analysis. Nothing fresh here, except a perceptive criticism of the "revealed preference theory" popularized by Starr in a paper in Science 12 years ago (165, 1232-1238). Parts II, III and IV cover the social and political consequences of risk-assessments. Here there is a good deal of interesting and controversial opinion.

Risk-assessment is only one of several operations necessary for the much broader discipline of decision-analysis, and it is a pity that it has been split off and isolated from the parent subject. For when you have made your statistical assessment (of, for instance, lives that would be saved by the wearing of seat belts in cars), and your guess as to how motorists perceive this risk, you still lack data essential for making a decision. The politician wants an answer to the question: "What is an acceptable risk?". But there is an antecedent question to that one: "Who, in a pluralistic democracy, has the right to decide what is an acceptable risk?'”. When the issue arises in Parliament, this is the sort of question which MPs ask. And what is the purpose behind a statement about risk-assessment? Is it to impose safety standards for which there is a public demand? Is is to reassure the public that some decision already
Society, Technology and Risk Assessment. Edited by J. Conrad. Pp.304. ISBN 0-12-186450-2. (Academic: 1980.) £15.20, \$35. Dealing with Risk: The Planning, Management and Acceptability of Technological Risk. Edited by R.F. Griffiths. Pp.144. ISBN 0-7190-0819-0/ 0-470-27136-1. (Manchester University Press/Halsted: 1981.) £11.50, \$19.95.

taken, for reasons nothing to do with safety, need not cause disquiet? Then there is the assumption, one I have myself made, that public perceptions of risk are irrational (for example the person who willingly indulges in some practice which exposes him to a $10^{-3}$ risk of death but who campaigns fanatically against some other practice which would expose him to a $10^{-7}$ risk of death). Irrational, no doubt, on the criteria applied professionally by scientists, but most of the British public are not scientists and their irrationalities are as significant for the decision-analysis as are the hard data from the statisticians. To exclude their views from the risk-benefit balance sheet would be to cook the books. Social intuition may appear to be a woolly concept compared with fault-tree-analysis, but it is likely to carry more weight in Parliament and in Whitehall.

Owing to considerations such as these, a good deal of research on risk-assessment seems peripheral to the issues that have to be decided by developers or planning authorities. This is the opinion of some of the contributors to the Battelle Institute workshop. What emerges from these papers is the impression that (in the words of Volker Ronge, from Germany)

decision-making processes have apparently come out to be risky in that they are no longer capable of producing sufficient social consent to outcomes that have to a large amount been "decided upon" outside the political realm.

The book edited by Conrad, then, enlarges our awareness (if not our understanding) of the sociological and political ingredients in decision-analysis. The book edited by Griffiths is a more pragmatic set of papers, most of them written by people who really have to make decisions about risky projects and who work at the coal-face of public opinion. It is therefore refreshingly practical. A safety adviser from industry sets out clearly how he has to compose his advice. No use to pretend that there is zero risk. Sooner or later some accident will happen and there will be fatalities. There is a temptation to rely on compared risks ("we should not spend money on raising the height of the handrails if the risk of falling over them is smaller than the risk of being harmed by toxic chemicals in the atmosphere'). But of course this sort of argument is not acceptable to the industry or to the public. The decision-maker is driven back to crude cost-benefit analysis: the cost of saving a statistical life. Thus (an example from Conrad's book) in the Netherlands it was considered whether to introduce earth leakage switches into domestic wiring systems. It would reduce the number of electrocutions by a factor of ten; but since the present risk is only $5 \times 10^{-7}$ per year, the cost per life saved would be of the order of $\$ 2$ millions.

It is no wonder that this sort of arithmetic is not commonly disclosed to the public in planning enquiries, nor, if it were, would it make much impression. In two chapters on hazard and risk in planning, two planners (one from the Cheshire County Council and the other from the Halton Borough Council in Cheshire) explain exactly what procedures they follow when there are hazards in the project being planned. The book is worth reading for these two contributions alone; for the experience of these two practical men may do something to remedy the most serious problem in risk-assessment, namely the alienation of the public toward those who have to decide, on the public's behalf, what is an acceptable risk. Risk, as Stephen Cotgrove points out in the concluding essay in Dealing with Risk, "is not just a statistical calculation. It is also a moral judgement about defensible conduct"'. It is the legitimacy of decisions made about risk, more than their accuracy, which is being called in question by public interest groups and which causes exasperating delays in what are often desirable developments. The open, empirical and unsophisticated procedures described by the planners from Cheshire, coupled with their willingness to take the public into their confidence, may do more to restore the legitimacy of planners than would volumes of research on risk-assessment.

These two books, together with the book Societal Risk Assessment (reviewed in Nature 289,$827 ; 1981$ ) should dispel any illusion that the problem: How safe is safe enough? is within sight of solution. But why, oh why, have we not yet heard evidence from actuaries who calculate insurance?

Lord Ashby is Chancellor of Queen's University, Belfast, and a Fellow of Clare College, Cambridge. 